AC 2009-1522: LONGITUDINAL CONTACT WITH INDIVIDUAL STUDENTS AS A WAY OF ENCOURAGING SELF-DETERMINATION IN CHEMICAL ENGINEERS

Paul Blowers, University of Arizona 


\title{
Longitudinal Contact with Individual Students as a Route of Encouraging Self-Determination in Chemical Engineers
}

\author{
Paul Blowers \\ Department of Chemical and Environmental Engineering \\ The University of Arizona
}

\begin{abstract}
It is difficult to have contact with individual students over a sustained period of time due to constrained schedules and competing time demands. However, frequent contact with individuals over time allows advisors to build student strengths in self-determination while tailoring advice directly to changing interests.

The talk will highlight advising opportunities from outreach, through retention, continuing to graduation, and post graduate interactions that fit within student progress towards their individual careers. Appropriate advising content for a technically rigorous chemical engineering program will be used as examples of how to motivate students towards exploring options and making decisions that open new doors to professional development. The issue explored is that self-determination comes from inside the student and that confidence in personal evaluation is fostered through directed activities throughout students' time with us.

Objectives that readers should be able to meet will be:

- $\quad$ to have the ability to identify points of contact where longitudinal contact can be encouraged

- $\quad$ to have the knowledge of how to remove impediments to longitudinal advising through reconstruction of advising duties in larger programs with many staff members, or through directed contact with students in smaller departments

- $\quad$ To have the ability to link student possibilities to exploratory activities that lead to selfdetermination

Students in chemical engineering are generally very strong in academic abilities, but often have not been exposed to a breadth of activities and possibilities that enable them to construct their own paths. Sustained advising contact has led to strong statistically-based success of students who have progressed through our program with approximately $30 \%$ of our graduates entering top ten chemical engineering graduate programs, $100 \%$ student placement of graduates almost every year, and a host of university-based, state, and national awards going to our students.
\end{abstract}

\section{Introduction}

Most faculty appointments in the United States carry the expectation that there will be a balance among different work activities[1-4]. The typical assumed split on a time percentage basis is $40 \%$ on research, $40 \%$ on teaching, and $20 \%$ on service, although those percentages vary in reality[5]. One way of meeting service obligations is for faculty to take on the task of advising students in their disciplines[4, 6, 7]. Activities in the advising area provides service to many constituents, including to the students, to the department, to the profession, and to our 
stakeholder companies, employers, and the general public. Students benefit directly from the close communication and exposure to ideas of an "expert" in the area of academic development. The department benefits directly by smoothing the progress of students through their programs while maintaining high standards and increasing statistical measures often used for evaluation of programs like retention, average student time to graduation, and student contact hours. The profession is improved by the production of students who are prepared to think rigorously about their own development and how to engage in life long learning. Stakeholder companies and employers benefit by a larger pool of graduates that may be more highly qualified than a student pool that had been unadvised. Finally, the general public benefits through the production of responsible citizens who contribute not only to the financial health of their local economies, but also through the goods and services provided by educated engineers.

While the benefits of advising were listed above, the purposes of advising are more focused on the students. Navigating engineering curricula is not easy for most students. There are many constraints placed on course offerings, timing of events, prerequisite courses needed for advancement, grade point needs, and other academic concerns. Students often struggle along the way when a situation occurs that moves them farther away from the norm of progress, and they can leave engineering or give up on higher education completely. Outside of the academic areas, students may need other institutional support to help them function well in the learning environment. These resources can be efficiently accessed after students are advised of their existence and how they can be taken advantages of. Examples of support students may make use of include tutoring help, psychological and counseling services, legal services, health care professionals, mediators, and many others. Getting the students the help they need when they need it enables them to stay focused on their coursework while managing their daily lives better.

The purpose of this paper to show how one form of advising has led to stronger interactions with students that lead to transformation of the students into professionals capable of self-determining their goals. This paper begins with a discussion of four commonly used structural advising models that set up the framework for student-advisor interactions. The paper then highlights some of the outcomes of one of the advising models, longitudinal advising, leads to more efficient use of faculty/staff time while enabling students to be involved in developmental activities. Main interaction points and timelines are discussed before some implications of retention are discussed.

There are many models for how student advising can be accomplished and a summary appears in Table 1 on the next page. One example commonly encountered by students could be called punctuated equilibrium. This is where students are required to meet with specific advising staff or faculty at certain gate-keeper events like the transition from being a pre-engineering major to being in a specific major, the transition from lower division (freshman/sophomore) status to upper division (junior/senior), or advancement to graduation through a formal degree check. Students may or may not ever meet with an advisor during other times during their academic career.

Another model for advising could be called a single pass through approach. This is one where there are designated advisors for each academic rank, for instance one or two advisors for freshman, one or two for sophomores, etc. In this approach, students have the opportunity to 
engage with at least four faculty during their time as students, giving them a broader access to more viewpoints and expertise. One problem with this approach is that it is inefficient.

Faculty/advising staff must spend time evaluating where each student is before moving on to the actual advising when they meet with a new advisor each year. Additionally, the advice may be the same that students have heard previously but then discovered did not help them; this is inefficient for both faculty and students.

A third mode of advising students is the least formal and could be called "catch as catch can". Students moving through a program organized around this theme do not have specific advisors for any point in their academic progress so they may not be able to get the help they need. They may not even know who to ask for help in constructing their class schedule for core courses, leading to disaffection and loss of motivation to continue.

A final method of advising students is almost continuous and could be called "longitudinal advising". . One faculty/staff member is responsible for a student during their entire program of study at the university, leading to long term and sustained contact over time. Faculty in this model get to know the students well and can provide the most relevant advice as needed because they know the students' abilities, their weaknesses, and what works well for them. The intimate and close contact allows the faculty member to write much stronger and more specific letters of recommendation for students when they apply for positions, graduate school admission, or scholarships, as well. Students get to know one faculty member well and this can enable them to know the faculty more as a person than just an institutional representative. The strengths of longitudinal advising are enhanced when combined with situational leadership approaches[8] or developmental advising[9] approaches preferred by students[10].

Table 1 - A summary of different advising modes and their pros and cons.

\begin{tabular}{|c|c|c|c|c|}
\hline Method & $\begin{array}{c}\text { Punctuated } \\
\text { Equilibrium }\end{array}$ & $\begin{array}{c}\text { Single Pass } \\
\text { Through } \\
\end{array}$ & $\begin{array}{c}\text { Catch as Catch } \\
\text { Can } \\
\end{array}$ & Longitudinal \\
\hline Definition & $\begin{array}{l}\text { Students meet } \\
\text { advisors at required } \\
\text { times for formal } \\
\text { advising }\end{array}$ & $\begin{array}{l}\text { Students rotate } \\
\text { through a series of } \\
\text { advisors, seeing } \\
\text { different ones at } \\
\text { different points }\end{array}$ & $\begin{array}{l}\text { Students self-seek } \\
\text { out help as needed }\end{array}$ & $\begin{array}{l}\text { Students see the } \\
\text { same advisor for the } \\
\text { entire undergraduate } \\
\text { academic career }\end{array}$ \\
\hline \multirow[t]{2}{*}{ Pros } & $\begin{array}{l}\text { Expectations for } \\
\text { students are well } \\
\text { known for timing of } \\
\text { meetings }\end{array}$ & $\begin{array}{l}\text { Students get to know } \\
\text { a variety of advisors } \\
\text { in many contexts }\end{array}$ & $\begin{array}{l}\text { Students can meet } \\
\text { with anyone for help }\end{array}$ & $\begin{array}{l}\text { Students get to know } \\
\text { one advisor well }\end{array}$ \\
\hline & & & & $\begin{array}{l}\text { Time efficiencies } \\
\text { Developmental } \\
\text { advising is possible } \\
\text { Information is } \\
\text { consistent }\end{array}$ \\
\hline \multirow[t]{2}{*}{ Cons } & $\begin{array}{l}\text { Students may not } \\
\text { know who to } \\
\text { approach for new } \\
\text { issues that are not } \\
\text { part of the formal } \\
\text { track }\end{array}$ & Time inefficiencies & $\begin{array}{l}\text { Students may feel } \\
\text { disconnected from } \\
\text { their planning }\end{array}$ & $\begin{array}{l}\text { Scheduling may be } \\
\text { difficult }\end{array}$ \\
\hline & & $\begin{array}{l}\text { Information may not } \\
\text { be consistent }\end{array}$ & $\begin{array}{l}\text { Students may not } \\
\text { know who to go to }\end{array}$ & \\
\hline
\end{tabular}

$\begin{array}{ll}\begin{array}{ll}\text { Information may not } \\ \text { be consistent }\end{array} & \begin{array}{l}\text { Students may not } \\ \text { know who to go to }\end{array}\end{array}$ 
This paper describes longitudinal advising of students, how it can be implemented through different contact points with students, and how it can lead to students being able to better control their own futures through self-determination. Motivating students is a strong focus, especially at critical points when many students may consider leaving engineering for other less challenging disciplines. The core set of skills that students must have upon graduation for success are then described, along with some subskills that may be conveyed for subdisciplines.

\section{A Sample Department Where Longitudinal Advising Has been Implemented}

The department and the local environment where longitudinal advising has been done appears next to highlight some of the characteristics that enabled this approach to be successful. The academic achievements and professional accomplishments of the students over the recent pass will also be highlighted to show the outcomes of this advising approach.

The chemical engineering department in this work has 14 faculty. These faculty members oversee one B.S. program in chemical engineering and M.S. and Ph. D. programs in both chemical engineering and environmental engineering. About 6 faculty members teach the 14 core B.S. chemical engineering courses and it is the B.S. population that will be the focus of the rest of the discussion.

All faculty members in the department are engaged in both teaching and research and there are no adjunct faculty who teach courses. The involvement of all faculty in all aspects of the department leads to more interactions among students and faculty. The student class size is about 55 at the sophomore level and between 30 and 40 students at the upper division junior and senior levels.

Core discipline courses are restricted to being offered only once a year and are fairly evenly spread over a 6 semester series. The hierarchical nature of the core courses mean it is critically important for students to work with an advisor to ensure they stay on track; deviation from the prerequisite courses delays student graduation by a full year in almost every case. One feature of the program and course hierarchy is that once students begin their sophomore year, they will be with those same peer students until graduation. This makes it easier for faculty to track student progress and to follow different cohorts.

The student population in the chemical engineering B.S. program is very strong academically while also being diverse. Roughly 50 percent of each graduating class is female, which can be compared to the rest of the college being $18 \%$ female. This difference between chemical engineering and the rest of engineering is similar to those of other programs. About 85 to $95 \%$ of each graduating class is composed of domestic students. Forty-eight percent of the students are enrolled in the Honors Program at the university, which is about 3 times higher than the general student population with an $18 \%$ involvement. Out of each graduating class of 30 to 40 students, there will be 2 or 3 National Merit Scholars. Approximately $75 \%$ of each graduating class has done research in a faculty lab before they graduate. The students in the program are arguably the best in the college and university. 
Student excellence in academic pursuits is evident at the local and national levels. At the college level, a chemical engineering student has been named the top student in the college $90 \%$ of the time, even though there are 18 different programs who nominate students each semester. At the university level, there are 10 or 12 students honored each year for being Pillars of Excellence, as selected by the Honors College. Out of the past 22 awardees, four have been chemical engineers. Also at the university level, three students in the past 6 years have been named the top undergraduate researcher in an internal competition. At the national level, students have been very strong in competition with other top chemical engineers at American Institute of Chemical Engineers conferences. In the last eight years, three students have been named as the best undergraduate researcher in poster competitions. It should be noted that the three national research awardees were not the same students as the local award, highlighting the depth of undergraduate research involvement. One student in the recent past was named the best chemical engineer in the country by AIChE after placing first in the oral competition at the national conference. Finally, students compete strongly at national level for scholarships and other awards. Four students in the past two years have been named Tau Beta Pi fellows and one was named the best engineer in the country as that organization's laureate. There have been numerous Udall scholars, NSF fellows, and one Fullbright award winner in the last three years.

Students compete strongly for both graduate school admission and for full time employment. One third of our graduates have consistently gone on to graduate school with about $95 \%$ of them going to $\mathrm{Ph}$. D. programs that are ranked in the top 10 or 20. Students have gone to graduate school for degrees in chemical, biochemical, biomedical, mechanical, and environmental engineering. Students have also gone on for advanced degrees in pharmacy, mathematics, law, and medicine. On the job front, all but 1 or 2 students each year will have accepted an employment offer or graduate school offer by the day of graduation. Typically, the students without offers were not pursuing options or had U.S. visa issues.

Part of the success of our students comes from their diverse outside interests and their strengths in them, which are fostered by faculty members through longitudinal advising. In the past three years, graduating seniors have been leaders in many areas. One student was a Division I athlete who placed sixth at the PAC 10 track championships in high jumping. Another student was named the best collegiate pianist at the university and then in the state, beating out M.S. and Ph.D. piano performance majors. One student routinely placed first or second in the American Tae Kwon Do Association's international weapons and hand-to-hand combat competitions. The Tour de Tucson is a 109 mile bicycle race that takes place late in fall semester, typically during a round of exams right before Thanksgiving. Three students have completed this race in the past three years, one of whom has cerebral palsy. Six students in the past three years have completed a marathon during the school year, two have completed full triathlons, and one third of the class two years ago completed the Tucson Half-Marathon. Students from the department have founded Engineers Without Borders, the Boxing Club, the Marathon Club, and the Table Tennis Club. On top of these students, approximately 1 single parent graduates each year.

Longitudinal advising is one of the mechanisms that allows the students to develop into the strongest candidates for their future endeavors and to achieve the successes just described. In addition, longitudinal advising eliminates many of the advising problems that students can create. This can help remove impediments to their progress through frequent major changing, 
often caused by students' difficulty in making long term decisions[11]. The sustained contact fosters long term and self-driven exploration by students. When longitudinal advising is not followed, students can attempt to "game the system" by shopping around for the advice they want. Students often move from advisor to advisor until they find one who will give them the answer they want, particularly in a department that has flexibility to treat special cases of students. This causes problems when students combine advice from several different sources about curricular issues, for instance, and try to create a plan of action that is inherently against the intentions of the faculty. An example may be replacing a core course with one from another department while also changing out another course that then leaves the student deficient in some of the content normally required to be mastered.

Another problem that longitudinal advising avoids involves hearsay or partial information. It is not unusual for students to partially remember some advising details from previous encounters with faculty and then misuse that partial information. Oftentimes, too, students turn to their peers for information and get poor advice on important decisions regarding their academic progress. Longitudinal advising helps ensure that the message is consistent because the messenger is the same each time the student gets help.

The ultimate goal of longitudinal advising in our department is to create engineering students who can self-direct their own career trajectories after their exposure to skills and tools that allow them to explore possibilities. The term "self-determination" is typically encountered in the context of countries and their right to determine internally, without outside influence, how to act. In this case, it means fostering self confidence[12] of students and exposing them to possibility. Discussions lead to an ability to self-direct that is the foundation of all other lifelong learning activities. The awareness students have of their own gaps in abilities and the possibilities they can achieve will guide them in their selection of new skill areas to build on throughout their lives.

It is good to point out here that advising is a pro-active way of building student's confidence by encouraging them to choose their own path and exploring their options. The role of advisor is to help students go not where the advisor has gone, and not where students' parents want them to go, or not even where students think they should go. It is to help them break through any of these preconceived barriers to find what types of work they are passionate about.

Longitudinal advising involves several access points between students and the advisor that span a considerable length of time. Pre-college recruiting can be used to begin the dialogue, while freshmen events and formal advising appointments can build from there. As students transition to upper division courses, they can explore their courses and external activities with their advisor. Many schools will have some gatekeeper events where students must meet certain standards prior to advancement and will need to mete with an advisor formally at that point. These gatekeepers may have many names but typically come at the undergraduate education mid-point as students transition from lower division to upper division classes or at the end of their academic career for a senior degree check. There are also many other opportunities as students move towards graduation. Interactions between advisors and students, focusing on how to motivate students to explore their own trajectories will be discussed next. 
Pre-college recruiting can be both formal and informal, ranging from meeting with students oneon-one to being large scale events with groups of students. Many high school students who have just completed their sophomore or junior years will travel with their families during the summer to explore universities, colleges, majors, and living conditions as they prepare to make their decision on where they will pursue their first degree. Interactions with these individuals are typically on a "drop-in" basis where the visiting families are directed to see an available advisor. More formal summer and academic year activities occur as well. These may include specific summer research institutes for pre-freshmen, outreach programs to local high schools, or mentoring programs with youth groups. Orientation events are another time when students formally meet with advisors to begin planning their academic program. Finally, recruiting dinners for special populations like underrepresented minorities or National Merit Scholars give other access points for advising.

Throughout the pre-college interactions, there are some strong foci for motivating students. One can question students about what they know about their potential major, addressing misconceptions and providing resources for them to explore the majors and opportunities. This is also a good point to begin assembling the background information about students that is critical to their success[13] and their families that will enable the advisor to work within that framework to select possible activities. Parents have strong influences on students' decisions[14] and knowing a student has a family where everyone has a Ph.D. in a discipline related to the student's choice is very different from knowing a student who is the first in their family to leave their small town to attempt a bachelor's degree. Rapport with students can begin to be built as advisors bridge their own experiences to what the students will soon be experiencing. Questioning the student about why they are choosing their major also allows the advisor to select appropriate exploration routes. If a student says they are choosing a discipline like engineering because they love math and its applications, then the advising can direct students to find independent research projects or summer programs where they will be exposed to these types of learning. Finally, a complete student background can be done by filling in information about the students academic background on grades, extracurricular activities, courses taken, and work experiences.

Freshman student advising tends to become more formal than pre-college interactions. There may be opportunities for access during a required freshman colloquium seminar series, through required courses, or through academic advising requirements[15, 16] for specific disciplines. Emails to students directing them to opportunities or to course requirements for prerequisites can help students get on track early for progress through their major courses[17]. There may be many self-sought interactions initiated by students, particularly those who are the most motivated. Course registration for an upcoming semester typically encourages students to seek out advice at that time. Some students will also find themselves on academic probation at the end of a semester and will need to formally meet with an advisor to come up with a plan to return to a successful trajectory. Motivational tools in cases like these are to discuss other students who have found themselves in academic distress who then went on to become successful in their endeavors. Exploratory activities may include finding the right expertise on campus to help students move past problems include seeing a psychological counselor, meeting with legal staff, or seeing evaluators for assessment of learning disabilities that may have emerged over time. 
Advising activities designed to foster self-reflection and investigation of career pathways can be built directly into required courses. This is particularly useful when it is done consistently and is evaluated formally as part of the student's academic performance. Assignments that have been used to do this successfully include a one page essay where students describe why they are interested in their major and what aspects of possible careers interest them after a short lecture on the possibilities. Another activity involves a lecture on resumes, their content, and how to structure them to be concise and attractive, followed by an assignment requiring students to submit a resume for critique and scoring. This activity has been done at the freshman level to motivate students to begin filling in gaps in the core areas of work experience, leadership, and scholarship. Sophomores and juniors can also benefit from this activity as they move towards graduation when it will then become too late for any new development. At the senior level, this activity can be done a final time to ensure students have presented their skills the best way possible as they begin to apply formally for permanent positions. Another senior activity that is useful in times of economic downturn is to require each student to weekly submit a list of contact information and copies of cover letters they have prepared and sent out that week as a formally evaluated assignment.

In addition to career related activities, academic advising ones can also be built into core courses. One assignment used at the sophomore level involves explaining the criteria students must meet for advanced standing and progression to the junior core courses, then requiring students to report their completed courses and grades so they can self-assess their readiness for continuation. More informal interactions can also be used for discussing opportunities when faculty are also the academic advisor. The few minutes before and after class as students transition into and out of the classroom provides time for individual advising on issues that students face in their immediate future. Specific needs can be addressed on the spot or more formal dedicated time can be scheduled at that point if the issues are more complex. Interactions like these are one strong advantage of having faculty members also advise students.

Classroom contact with advisors is useful for identifying patterns in student behavior that may impede their success. Examples include addressing students who always put themselves down, students who lack confidence, or students who are shy and may need to be introduced to their peers to begin interacting. Students who rely too much on team members for projects can also be identified and approached about how their actions may harm them over the long term. Students who have serious character flaws can also be addressed to help them find methods of mediating their flaw. Racism, sexism, and the inability to communicate have been successfully addressed informally and off-line out of the classroom after observing student interactions in the classroom.

Outside of the classroom, contact for motivating students can continue to occur as the students move towards graduation. Emails to course listserves or student organizations can direct students to applications for scholarships, opportunities for developing leadership skills, internships, and summer research programs. Connecting company recruiters with students who fit the desired skill sets can also foster develop of student knowledge of their more immediate career options. Encouraging students to diversify their experiences and become involved is another strategy in helping them seek out new challenges that strengthen their portfolio. 
A final academic requirement of a formal senior degree check is another opportunity to motivate students to examine their career trajectory. Typically, this evaluation occurs during the semester prior to students registering for their last semester's courses. Longitudinal advising should have prepared students to meet all graduation criteria at this point. However, students can still change their career path slightly through taking on an independent study project or by selecting electives appropriate for the careers they are interested in.

Graduation may not end all interactions between students and their past academic advisors. Students may continue to seek help in developing their career paths over extended periods of time. Students may request letters of recommendation for graduate school applications. Students may need help in resolving conflicts where students may want an outside view of their situation in order to sound out good routes for advancement. Students may want feedback on performance evaluations and how to handle criticism in a proactive way so they can select development opportunities. Encouraging continuing growth is possible with more longitudinal contact.

While past students may often want help, they are also a resource for faculty and their current students. Alumni can be contacted for help in placing students who are looking for internships or permanent employment, especially in cases where the past and current students share some common traits or connection. Past graduates can also be invited back into the classroom to hold discussions about their career paths as a motivational interaction. Connections over time can lead to donations of time, expertise, or money to the department through individual philanthropy.

\section{Motivating Engineering Students and Retaining Them}

Motivating students appropriately is possible through knowledge of their academic and family backgrounds combined with a long term understanding of the career possibilities students have already explored through the choices they have made. Sometimes, students need more focused help when they are transitioning through a difficult phase in their lives. Students may find themselves in a new family situation through birth, death, divorce, or military service. Students may find themselves working to support themselves while pursuing their degree. Overcoming illnesses or accidents can also lead to academic struggles. Rising to challenges when failure seems imminent can be fostered by sharing stories of students who have been successful after a circumstance similar to the one the struggling student is facing.

Engineering faces some special challenges in motivating students to stay enrolled. The coursework is often regarded as being the most rigorous and difficult on campuses. The large body of background knowledge needed to begin serious study of the core discipline eliminates many students from programs. However, the heavy courseload and academic requirements of being a full time engineering student can frustrate even the best students when they see their friends in other majors seemingly making high grades without a similar investment of effort or time.

Engineering offers some unique opportunities for motivation as well. The financial rewards of remaining in engineering over other disciplines, especially in difficult economic times, and the larger number of employment opportunities are a direct incentive for students. The constant and 
steady demand for qualified applicants from engineering is stable in both good and bad economic times. Students can be motivated by the intellectual challenge that not everyone can successfully complete the coursework while they have the satisfaction of progress. And, as social problems mount due to resource constraints, the ability to help others through their profession is another strong motivator.

There are certain core skills that students must have in a discipline in order to become successful. Fostering those skills can be done through longitudinal advising. It is assumed that graduates will be technically competent in their selected fields. However, students must have strong written and oral communication skills. These skills can be strengthened in students by suggesting they participate in writing workshops, become student ambassadors or tour guides, or through tutoring other students. Teamwork is another "soft" skill expected in students. Encouraging students to join clubs and move into officer positions over time allows them to build these skills in addition to any team based projects that may be required of students in the classroom. Through extracurricular activities students will also gain a better appreciation of how to learn independently, how to be flexible, and how to be persistent.

There are some gatekeeper assessments used for controlling student access to some opportunities after graduation. Students must have a resume for graduate school applications and permanent employment. A resume well populated with leadership activities in addition to relevant work experience helps candidates secure better offers. A strong GPA may also be needed for some possibilities like admittance to a highly ranked graduate program or receiving an offer from some companies that may have a 3.5 GPA requirement. Students who can demonstrate a good life balance through outside activities have advantages over other students. Longitudinal advising allows students to start with smaller activities and continually leverage their experiences into higher level interactions. One example is for students to become a general member of a club one year and then transition into a position with the officers of that club the following year.

For some disciplines, other gatekeepers include professional certifications students must fulfill. This may include passing the Fundamentals of Engineering exam or completing hazardous waste management training through OSHA, among others. Any activities students can do ahead of time to prepare for their successful completion of these other demands will make them more attractive for hiring. Longitudinal advising allows information about all of these topics and their importance to be shared with students when they still have time to enhance their development.

Longitudinal advising appears to enable our program to continue to recruit and retain strong students. National enrollment trends show that total engineering enrollment has been dropping slowly since about 2003[18]. Chemical engineering enrollments have dropped from about 30,000 to 20,000 nationwide in the U.S. in the last decade. Interestingly, chemical engineering freshmen enrollments have risen slightly nationwide, but overall enrollment has dropped. Our enrollment, while it was dropping prior to enacting longitudinal advising has now rebounded. We've had graduating classes of 26, about two years into using longitudinal advising, that have risen to 32, 40 and 36 in the last three years. We are retaining the students once they encounter us in our courses and through advising. While other changes also occurred over the last several years in our department, advising has been noted as a strong point of our department in senior exit interviews. 


\section{How to Create Opportunities for Longitudinal Advising}

Much time has been spent discussing the benefits of and how to implement longitudinal advising in the framework of undergraduate experiences. The discussion will now turn to how longitudinal advising can be encouraged at the departmental or institutional level. One recommendation is to assign pre-majors or freshman directly to one advisor who they will be engaged with as soon as they have contact with their major, possibly even prior to students seeking out help. This advisor would then remain their advisor until they complete or leave the program. Another recommendation is to only have advising by those faculty or staff who are passionate about this activity. A mediocre to poor advisor who followed a student longitudinally could do more damage to student motivation than a short interaction with a good advisor can compensate for.

Department heads and curricular chairs can foster connections between faculty and advisors if they are not the same people by hosting short meetings oriented around sharing information. Advising deadlines and methods of fostering self determination within students as discussed previously in this work can be shared with faculty to be incorporated into courses. Faculty members, in turn, can provide a list of concerns students have voiced about issues relevant to them, or can help in identifying those students who may face special challenge so advisors can follow up. Professional staff who have contact with students could also be included in this meeting. One meeting perhaps once a semester would allow for contact and sharing of this information.

At the college and university levels, adequate training and exposure to student resources should be provided to all advisors[19]. A single pamphlet that organizes all support offices like disability resources, tutoring, counseling, etc., could be provided at the beginning of each year to remind faculty of their existence in a concise place. Release time from other service duties will also enable faculty and staff to provide the best in advising services longitudinally. Recognition of accomplishments in this service arena will reward faculty for the patience and determination to help students in reaching their highest levels of achievement.

\section{Conclusions}

Longitudinal advising is a way of consistently motivating students to reach their highest potential. One plants the seeds of ideas that may grow fruit over time through exposure to new skill areas or information. Students can learn how to be flexible through evolving interactions with their advisor when they adapt to students' changing needs. Impediments to personal growth can also be removed when they are small or manageable. The sustained interactions over long periods of time allow advisors to know the students well and help them transition to lifelong learning professionals who are successful. 


\section{References}

1. Seldin, P., Evaluating Faculty Performance: A Practical Guide to Assessing Teaching, Research, and Service. 2006, Bolton, MA: Anker Publishing.

2. Link, A.N., A time allocation study of university faculty. Econ. of Educ. Rev., 2008. 27(4): p. 363-374.

3. Mitchell, T.R., The academic life: Realizing changes needed for business school students and faculty. Acad. Manag. Learning Educ., 2007. 6(2): p. 236-251.

4. Kuhn, T., Padak, G., Is academic advising a discipline? NACADA J., 2008. 28(2): p. 2-3.

5. Collins, M.A., Zinskie, C. D., Keskula, D. R., Thompson, A. L., Institutional responsibilities and workload of faculty in baccalaureate dental hygiene programs. J. Dental Educ., 2007. 71(11): p. 1403-1413.

6. McCormick, C.B., Barnes, B. J., Getting started in academia: A guide for educational psychologists. Educ. Psych. Rev., 2008. 20(1): p. 5-18.

7. Balogun, J.A., Sloan, P. E., Gemain, m., Core values and evaluation processes associated with academic tenure. Perceptual and Motor Skills, 2007. 104(3): p. 1107-1115.

8. Lerstrom, A.C., Advising Jay: A case study using a situational leadership approach. NACADA J., 2008. 28(2): p. 21-27.

9. $\quad$ Huggett, K.D., Advising in Undergraduate Honors Programs: A Learner-Centered Approach. NACADA J., 2004. 24(1\&2): p. 75-87.

10. Smith, J.S., First-Year student perceptions of academic advisement: a qualitative study and reality check. NACADA J., 2002. 22(2): p. 39-49.

11. Frimin, M.W., MacKillop, L. M., Frequent major changing: Extrinsic and intrinsic factors. NACADA J., 2008. 28(2): p. 5-13.

12. McDonald, M.L., Advising high-ability business students. NACADA J., 2003. 23(1\&2): p. 58-65.

13. DesJardins, S.L., Jie, W., An analytic model to assist academic advisors. NACADA J., 2002. 22(1): p. 3244.

14. Simmons, A.N., A reliable sounding board: Parent involvement in students' academic and career decision making. NACADA J., 2008. 28(2): p. 33-42.

15. Sams, W.P., Brown, L. S., Hussey, R. B., Leonard, M. J., The development, implementation, and assessment of a systematic academic advising program for exploratory first-year students. NACADA J., 2003. 23(1\&2): p. 75-85.

16. Gordon, V.N., The Evolution of Academic Advising: One Institution's Historical Path. NACADA J., 2004. 24(1\&2): p. 17-23.

17. Schwebel, D.C., Walburn, N. C., Jacobsen, S. H., Jerrolds, K. L., Klyce, K., Efficacy of intrusively advising first-year students via frequent reminders for advising appointments. NACADA J., 2008. 28(2): p. 28-32.

18. National Trends - Report 0806D, Undergraduate Engineering Enrollments Overall are Declining Individual Engineering Discipline Trends Vary Significantly, Houghton, MI, August 2006.

19. Waters, T., Faculty socialization into the advising role: An examination of information and information sources that shape role learning. NACADA J., 2002. 22(1): p. 15-25.

\section{Biographical Sketch}

Paul Blowers received his PhD from UIUC in 1999 and has been a professor in chemical and environmental engineering at the University of Arizona since that time. He has been recognized as a top educator at the departmental and regional levels and in the past year was recognized as the best faculty academic advisor at his institution. He then went on to be selected as one of the top four faculty advisors in the U.S. by the National Association of Academic Advisors. 